\title{
Entrevista
}





\section{Entrevista al ministro de la Producción, Piero Ghezzi}

Gracias por recibirnos, señor ministro. ¿Cuál considera usted que es la herramienta más eficaz para que un productor artesanal tenga mejores ingresos? ¿Qué apoyo brinda el Estado a estas personas además de los posibles subsidios que puede realizar?

En realidad, la artesanía excede el mandato del Ministerio de la Producción, pero tiende a ser apoyada a través de sites artesanales, los cuales son centros de innovación tecnológica que han probado ser muy eficaces como una manera de transferir tecnología y así aumentar algo muy importante para todos, la productividad. Si queremos que nuestros ciudadanos tengan mayores ingresos, debemos ser más productivos; $\mathrm{y}$, en última instancia, el objetivo del Plan de Diversificación Productiva, que fue lanzado por el Ministerio de la Producción, es aumentar la productividad.

Precisamente, uno de los objetivos del Plan de Diversificación Productiva es "ampliar la canasta exportadora de la economía", donde se detalla como una medida el financiar a 268 emprendimientos y veinte incubadoras de negocios con el programa Start-Up Perú. ¿Cómo se viene implementando esta medida, señor ministro? ¿Qué otros proyectos similares sugiere para los próximos años?

A fines de agosto de 2014, financiamos ya 23 emprendimientos y cuatro incubadoras a través del Fondo para la Innovación, Ciencia y Tecnolo- 
gía (FINCyT), y seguimos en el proceso de encontrar emprendimientos interesantes que eventualmente puedan resultar como actividades exportadoras. Es importante resaltar que el Perú, en los últimos treinta años aproximadamente, ha mantenido una canasta exportadora con un componente de minería, un componente importante de pesca, algo de textiles y poca manufactura, lo cual generó una canasta poco sofisticada, con poca innovación y tecnología. Por ello, lo que estamos tratando de hacer, con una serie de iniciativas en el Gobierno, tanto el Ministerio de la Producción como el Concytec, es fomentar la innovación, área a la cual no se han dedicado muchos recursos, y con esto también se busca lograr una canasta exportadora más tecnológica e innovadora.

Como parte de la modernización de la gestión pública, se están implementando políticas como la simplificación de trámites. ¿Cree usted que la simplificación de los trámites que se siguen para la obtención de los instrumentos de gestión ambiental perjudicaría de alguna manera la realización de estudios adecuados del impacto ambiental, que tendrá la actividad a desarrollar por los empresarios?

Es muy importante entender que la idea, en general, es mejorar el ambiente de negocios en el país sin poner en riesgo la sostenibilidad del ambiente, sin generar empleo precario. Hay una serie de situaciones donde los trámites son excesivos, y el Estado peruano ha mostrado cierta inercia en ello, por lo que se han seguido, no solo en el tiempo de los trámites, que suele ser excesivo, sino que de facto los tiempos han sido más largos de lo que se decidió. En ese sentido, nosotros hemos decidido atacar frontalmente el problema de la excesiva burocracia, cortando tiempos, reduciendo lo que causa demoras, eliminando trámites innecesarios, utilizando la tecnología, porque también hemos observado que hay un excesivo empapelamiento. Con todo eso, lo que buscamos eventualmente es ir hacia un gobierno electrónico mucho más simplificado y tecnificado. Entonces, estamos haciendo, desde el Ministerio de la Producción, avances importantes, y estamos incorporando también a otros ministerios en este proceso de simplificación administrativa. Queda claro que no todos los problemas del Perú son la simplificación administrativa ni la informalidad, pero cuando los trámites son muy engorrosos y largos contribuyen a malas prácticas, al ciudadano de a pie se le hace perder mucho tiempo y eso es una ineficiencia con la que el país pierde. 
Considerando que una de las principales líneas de acción para la implementación del Plan Nacional de Diversificación Productiva es mejorar la política educativa, y teniendo en cuenta que de acuerdo a la nueva ley universitaria los estudiantes tendrán que realizar tesis para egresar, ¿cree usted que esto es una buena oportunidad para incentivar a los estudiantes, principalmente de ingeniería, a realizar trabajos de investigación innovadores sin que ellos se preocupen por el costo que eso pueda implicar, para solucionar de alguna manera las fallas de la política industrial moderna? ¿Se ha pensado ejecutar proyectos de financiamiento para estos trabajos de investigación?

El capital humano es el futuro del país, y ese capital es importante para una nación que quiere tener una canasta de exportación más sólida y sofisticada, pues necesita más mano de obra preparada, y como nuestro futuro son los jóvenes, los cuales son más audaces que mi generación, estamos incentivando, a través de fondos como el FINCyT, esa cultura de emprendimiento, la cual debe ser complementada con formación técnica y profesional, porque uno de los sesgos que hay en la economía peruana es que un porcentaje muy alto de la población termina estudiando carreras universitarias y no lo suficiente en carreras técnicas, que es lo que ahora más demanda el mercado. Por ejemplo, en países como Alemania y Suiza existen las carreras duales, trabajos duales, donde se estudia y trabaja a la vez, muy relacionados con el sector privado, y es en lo que debemos avanzar en el Perú. Esto es parte del plan en la medida en que es condición necesaria para la sofisticación de una canasta productiva importadora del país, pero acá está liderado por el Ministerio de Educación y el Ministerio del Trabajo.

\section{¿Cuáles son las principales propuestas de la Ley General de Acuicultura?}

Aún estamos en proceso de trabajo de esta ley, por lo cual no podemos explicar las propuestas. El problema que existe con la acuicultura en este momento es que es muy pequeña para el país. Mientras que en el resto del mundo hay alrededor de cincuenta y cincuenta en términos de pesca extractiva y acuicultura en el sector pesquero, en el Perú estamos hablando de un 98 o $99 \%$ de pesca extractiva y 1 o $2 \%$ de acuicultura, y no solo eso, sino que dentro de la actividad acuícola que existe, el 60 $\%$ es conchas de abanico, lo cual en realidad nos lleva a decir que es una acuicultura de nivel básico en la medida en que se está explotando un banco natural y no como consecuencia total de una actividad que viene 
de la mano del hombre. Acá tenemos un potencial altísimo, es un problema de posibilidad, de expandir a otras especies. No es necesaria una exención tributaria, como ocurre en la agricultura por ejemplo, sino que es importante fomentar la innovación, lo cual hemos mencionado en más de una ocasión, pues hay fallas de mercado porque se hace poca innovación. Por ello, nuestra intervención como Ministerio de la Producción se hace por medio de medidas que ayuden a subsidiar la innovación, labor que hacen fondos como el FINCyT, que otorgan dinero para impulsarla.

Se sabe que nuestro país es uno de los máximos exportadores de pescado y sus derivados, como la harina de pescado, lo cual se ha visto afectado por la extracción de recursos pesqueros en tallas menores de acuerdo a lo establecido por la Ley. ¿Considera usted que ya existen medidas normativas implementadas para frenar esta situación, $o$ aún no se han implementado políticas públicas idóneas?

Sí existen medidas normativas implementadas; justamente, en este año hemos tenido mucho éxito en cerrar zonas y poner vedas cuando se ha visto que la actividad pesquera está llena de muchos juveniles. Una experiencia que deberíamos replicar en el resto de la pesquería es que tenemos que trabajar con mucha "cintura", e ir reaccionando a la realidad. Existen leyes marco, pero las condiciones climáticas y del mar en general son muy cambiantes, por lo que debemos tener políticas públicas adecuadas a nuestra realidad y con base en ello ir reaccionando. Entonces, por ejemplo, si vemos que en los barcos se van descargando muchos juveniles, tenemos que ir cerrando algunas zonas. Esto permite distinguir los que tienen tallas menores a las mínimas. Nosotros hemos realizado muchos decomisos en la pesca artesanal precisamente por este último aspecto.

El problema natural de este año es el Fenómeno del Niño, que si bien no ha aumentado mucho la temperatura del mar, sí ha ocasionado cambios importantes en donde está el recurso. Lo que estamos haciendo en pesquería es aceptar la realidad de que la situación es cambiante y que más importante es ser capaz de adaptar las políticas, es decir, tener políticas adaptativas, para tener mayor oportunidad de maximizar los recursos, de mantener la sostenibilidad marina, porque el peor negocio que podemos tener como país es que se nos acaben los recursos. 


\section{¿Cómo se plantea desarrollar una pesca artesanal sostenible?}

Algo que estamos haciendo en este gobierno es dar un énfasis muy importante a la pesca artesanal. Uno de los aspectos en los que estamos trabajando es la modernización radical de los desembarcaderos pesqueros artesanales (DPA). En el Perú, a inicios de este gobierno, no contábamos con ninguno de los 43 DPA adaptados a las normas sanitarias, que realmente fueran óptimos para el consumo humano directo (CHD); en cambio, en este momento, tenemos por lo menos tres ya adaptados, y lo que queremos es que al final de este gobierno contemos con por lo menos veinte. Pero esto no termina ahí, porque hay que asegurar que la cadena fríos se continúe, que los DPA estén bien administrados y se continúe dando créditos a los pescadores en términos de aparejo de pesca, embarcaciones nuevas, formación, etc.

Creemos que la pesca artesanal es muy intensiva en mano de obra, demanda mucho empleo, y por ello el proceso de formalización ha llevado tiempo. Por ejemplo, algo real es que los jóvenes tienden a formalizarse de manera más rápida que los padres, porque llegan a entender los beneficios de la formalización con mayor claridad, por lo cual están más predispuestos; pero, lamentablemente, la informalidad, al ser un problema profundo, debe trabajarse de manera transversal y continua, pues no solo es un problema económico sino también cultural y social.

¿Cuáles son las expectativas que tiene el Ministerio de la Producción para el programa "Compras a MYPErú", más allá de gestionar compras directas a las mype para incrementar sus capacidades técnicas de producción?

Por este año, con la recesión de la economía, estamos haciendo compras a MYPErú por un monto de aproximadamente veinte millones de soles en bicicletas, carpetas, uniformes, cocinas, para los programas sociales, y allí nosotros queremos ser el eslabón entre la demanda del Estado y las mype. Porque ha sucedido en el pasado que el Ministerio de la Producción quería comprar bicicletas y no había producción local, por lo cual teníamos que importar, y eso era realmente una pena. Eso significaba no haber sido a veces lo suficientemente flexibles en las especificaciones de la bicicleta, pues podíamos haber encontrado alguna que cumpla con el objetivo. Al respecto, hemos sido bastante activos para enlazar a los ministerios, y creo que se cumple con los objetivos: prime- 
ro, incentivar la demanda interna cuando nuestra economía se había desacelerado; segundo, aumentar la producción, el empleo y lograr escala para las mype, para lo cual hemos acordado con el Presidente y el ministro de Educación que esto sea una demanda continua, porque de nada sirve comprar en un año trescientas mil bicicletas y que al año siguiente ya no exista demanda, por lo que las mype se verían obligadas a cerrar, cuando lo ideal es tener una demanda continua, comprando, por ejemplo, cincuenta mil bicicletas en seis años. 